\title{
El proceso legislativo en México: la eficiencia de las comisiones permanentes en un Congreso sin mayoría
}

\author{
Luisa Béjar Algazi,* Sergio Bárcena Juárez**
}

Perfiles Latinoamericanos, $24(48)$

2016 | pp. 111-140

DOI: $10.18504 / \mathrm{pl} 2448-005-2016$

\begin{abstract}
Resumen
La forma de evaluar la eficiencia legislativa de las comisiones permanentes en México ha omitido hasta ahora la necesidad de construir coaliciones para lograr la aprobación de cualquier ley por la ausencia de una mayoría cohesionada y estable en el Congreso. En este contexto, el presente artículo se pregunta cómo abordar esa tarea. Parte de la idea de que cualquier esfuerzo en ese sentido requiere un conocimiento más preciso y sistemático de las actividades que realizan las comisiones permanentes en esas circunstancias, así como de las habilidades de su presidente para conducir ese proceso.
\end{abstract}

\begin{abstract}
The way to assess Mexico's Standing Committees efficiency in the lawmaking process has so far skipped the need to build a coalition for each bill due to the lack of a cohesive and stable majority in Congress. In this context, this paper focuses on how to cope with that task. It assumes that any effort to that effect needs a deeper and more systematic understanding of the activities done within it in such circumstances, and of the ability of his president to steer that process.
\end{abstract}

Palabras clave: Congreso, comisiones permanentes, partidos, proceso legislativo, eficiencia, liderazgo, presidente de comisión.

Keywords: Congress, standing committees, parties, legislative process, efficiency, leadership, committee chair.

* Doctora en Ciencia Política por la unam, profesora-investigadora titular "C" de tiempo completo en el Centro de Estudios Políticos de la Facultad de Ciencias Políticas y Sociales de la unam.

** Doctor en Ciencia Política por la Unam, profesor de tiempo completo del Departamento de Derecho y Relaciones Internacionales del ITESM, Campus Ciudad de México. 


\section{Introducción ${ }^{1}$}

A pesar de la creciente importancia de las comisiones permanentes del Congreso mexicano en la elaboración de la ley (Nacif, 2004; Dávila \& Caballero, 2005; Béjar, 2009; Aparicio \& Langston, 2010), la forma de evaluar su eficiencia se ha reducido a considerar el arreglo institucional con el que desarrollan su labor como el dato más relevante para explicar el número de iniciativas dictaminadas por sus miembros. Del sistema de partidos solo se ha destacado la necesidad de construir coaliciones mayoritarias para lograr su aprobación. El modo en que esta cuestión ha sido solventada, por lo tanto, se ha omitido en el análisis. O dicho de otra manera, se han ignorado las actividades que cumplen las comisiones cuando en la legislatura se carece de una mayoría estable.

A pesar de ello, la literatura sobre el tema establece claramente que un elemento central para abordar la cuestión es observar si en el Congreso se dispone de un partido cohesionado y con las curules necesarias para aprobar por sí mismo la ley (Aldrich \& Rohde, 2001; Cox \& McCubbins, 2005). Cuando eso sucede, todos sus órganos internos se orientan al logro de las metas colectivas de los legisladores de la fórmula. Si esa condición se halla ausente, su comportamiento sigue otro patrón. Esto ha sido acreditado en el caso de las comisiones permanentes de la Cámara de Diputados en Argentina (Calvo \& Sagarzazu, 2011a, 2011b), enfocadas a enmendar las iniciativas a ser votadas por la asamblea hasta hacerlas aceptables para la Comisión de Labor Parlamentaria, órgano encargado de asegurar la mayoría requerida para su aprobación.

Sin un Congreso con mayoría, en México se reproduce una situación similar. Esto se ha hecho patente, en especial, al tratar de sacar adelante diversas propuestas de ley sin el consenso de por lo menos dos de los tres principales partidos del país (Alemán, 2006). A las dificultades impuestas por la formación desde 1997 de gobiernos sin mayoría (Casar, 2008; Nacif, 2004), se ha sumado además la creciente influencia de los gobernadores y otros liderazgos subnacionales sobre el porvenir de los legisladores como consecuencia de dos factores. Uno, la alta competitividad alcanzada por los comicios en buena parte del territorio nacional (Méndez, 2006). Dos, la activación de un federalismo fiscal cada vez más exigente en su solicitud de recursos para los estados y los municipios (Díaz-Cayeros, 2004; Merino, 2010).

1 Los autores agradecen el apoyo del Programa de Apoyo a Proyectos de Investigación e Innovación Tecnológica (PAPIIT) de la Dirección General de Asuntos del Personal Académico (DGAPA) de la UNAM al proyecto IN305315: "La participación social en la construcción de la agenda legislativa del Congreso Mexicano". 
Como resultado de esas transformaciones, las comisiones permanentes de ambas cámaras del Congreso figuran ya como "celosos guardianes" (gatekeepers) de las iniciativas que podrán ser votadas por el Pleno, pero también como elementos imprescindibles en lo relativo a la forja de la ley. A pesar de ello, los estudios sobre su intervención en el proceso legislativo no han avanzado más allá de evaluar su capacidad para formular dictámenes bajo el supuesto de que a un mayor número de casos tramitados, más eficiente es su labor (Nacif, 2004; Casar, 2008; Béjar, 2009; Aparicio \& Langston, 2010).

Juzgar con este simple dato el trabajo realizado por sus miembros plantea varios problemas. Para empezar, no distingue la diversa relevancia de cada iniciativa en términos de la población afectada por sus disposiciones, ni de su posible impacto en el desarrollo del país. Trata por igual todos los temas, lo que equivale a olvidar la complejidad técnica involucrada en algunas piezas, cuando no la conflictividad que estas pueden suscitar debido al tipo de intereses afectados. Por último, ignora un hecho contundente. Ya que la ley no impone ninguna acotación a la facultad de los legisladores de proponer nuevas leyes o reformas es común que ellos utilicen ese recurso para promover su carrera; esto es, para presentar propuestas enfocadas a atender las demandas particulares de sus votantes potenciales, aun a sabiendas que estas no contarán con el apoyo de su grupo parlamentario, mucho menos de la asamblea. Bajo ese lente, en consecuencia, el déficit en la eficiencia de las comisiones para dictaminar las iniciativas que le fueron turnadas por la Mesa Directiva durante la legislatura es algo que puede darse por descontado.

A diferencia de ese cuerpo de literatura, en este artículo se argumenta que sin mayoría legislativa, la eficiencia con que las comisiones permanentes llevan a cabo esa labor no es independiente de la disposición de las dirigencias partidistas - léase, los coordinadores y su círculo más cercano- para superar los retos impuestos a la expedición de la ley en al menos dos frentes. El primero, descentralizada ya la carrera de sus legisladores, para ejercer el control positivo y negativo de la agenda legislativa, en lo relativo a los asuntos de su interés. El segundo, para impulsar la negociación de un dictamen capaz de sumar la mayoría requerida para su aprobación.

Las comisiones colaboran en la consecución de ambos propósitos a través de tres actividades. Inicialmente, coordinan la procuración de información y su discusión entre los distintos actores - tanto políticos como sociales- preocupados por influir en las leyes y las políticas públicas bajo su jurisdicción. Cuando, en virtud de la diversidad de intereses afectados por la negociación, la toma de decisiones se complica, participan en la persuasión de los "indecisos" promoviendo el intercambio de votos por recursos focalizados a objetivos específicos. Por último, contribuyen a movilizar el voto con la sustitución de los "disidentes" o críticos intransigentes de los acuerdos pactados en su seno. 
En tanto principal canal de comunicación entre las comisiones con los liderazgos de los grupos parlamentarios, el presidente de cada comisión tiene bajo su responsabilidad la conducción de estas actividades. Su habilidad para resolver problemas y conflictos constituye, en consecuencia, un referente fundamental en el grado de eficiencia alcanzada por la unidad a su cargo. Su capacidad para favorecer la confección de leyes o reformas susceptibles de ser aprobadas en la legislatura, sin suscitar el veto del Ejecutivo destaca, sin embargo, como el activo más importante en ese aspecto.

Para su exposición, este artículo se divide en cuatro apartados. En el primero, se discute la literatura centrada en el estudio de la relación entre los partidos y las comisiones, así como el modelo propuesto para medir su grado de eficiencia legislativa. En el segundo, se revisa el diseño institucional del proceso legislativo en México. En el tercero, se analizan las actividades realizadas por las comisiones permanentes en la Cámara de Diputados. Por último, se reflexiona sobre los hallazgos del estudio y sobre una posible agenda de investigación para el futuro.

\section{¿Comisiones o partidos?}

Hasta hace poco, la atención de los especialistas giró en torno al Congreso estadounidense, provisto de una mayoría más o menos cohesionada tras la introducción de importantes ajustes en su diseño institucional para reforzar la intervención de los partidos en la hechura de la ley. La recuperación de esas organizaciones como factor de ordenación del proceso legislativo quedó plasmada en una generación de estudios apoyados en el supuesto de que, lejos de responder al interés de todos los legisladores, las comisiones permanentes básicamente expresan las preferencias de la mayoría.

En esa línea, Aldrich \& Rohde (2001) advierten que la consecución de cualquier objetivo partidista en buena medida depende de la cohesión mostrada entre sus miembros (conditional party government). Cuanto más homogéneas son sus preferencias mayor es la disposición de aquellos a delegar en sus líderes las posturas del partido en el Congreso. Algo similar sucede cuando arrecia la confrontación entre la mayoría y la minoría por alguna política. En la versión del partido como un cártel de tipo procedimental (procedural cartel theory), Cox \& McCubbins $(1993,2005)$ parten de la idea opuesta. Desde su visión, el éxito de las reformas impulsadas por la mayoría depende más de su capacidad para ejercer el control negativo de la agenda, que de la disciplina de sus integrantes. Vale decir, de evitar la incorporación en el orden del día de la asamblea de propuestas contrarias a las preferencias del partido, o con el riesgo 
potencial de romper la unidad en el voto de sus legisladores. En consecuencia, su liderazgo tratará de impulsar un arreglo procedimental en el Congreso con el fin de delegar exclusivamente en ellos la conducción de los órganos encargados de formular la ley.

A condición de incorporar los ajustes pertinentes, la "teoría del partido cártel” puede ser también útil para analizar el comportamiento de algunos Congresos latinoamericanos (Jones \& Hwang, 2005). El más importante de ellos es quizás la fuerte influencia ejercida por los partidos de la región sobre el proceso legislativo, sobre todo cuando en algunos casos el sistema electoral y las reglas para la selección de candidatos apuntan — como en el estadounidense- a promover la descentralización, y al incremento de la influencia de actores del orden subnacional sobre la carrera política de los legisladores (Crisp et al. 2004; Desposato, 2004; Carey, 2009).

Como quiera que sea, asegurar la aprobación de las propuestas de ley que logran pasar el control del liderazgo del partido o la coalición mayoritaria es casi siempre una labor compleja. Según Gary Cox (2009), las tácticas para asegurar los votos requeridos para ello son similares a las utilizadas en los comicios. A este respecto, dicho autor sugiere la necesidad de poner en marcha tres tipos de actividades. Uno, de coordinación, entendidas como la realización de actividades enfocadas a modificar el número y el tipo de opciones entre las que el legislador (o el votante) "duro" del partido puede escoger. Dos, de persuasión, referidas al intercambio de recursos por votos a fin de modificar el sentido de sus preferencias. Tres, de movilización, enfocadas a influir en su decisión de apoyar en el Pleno la agenda legislativa negociada. Si el liderazgo de la mayoría solo se enfocara a persuadir, léase comprar votos, para quienes pueden cambiar el resultado final del proceso legislativo o electoral (Stokes, 2005), su confiabilidad como agentes del partido sería bastante limitada. En cambio, añade Cox, al enfatizar en el esfuerzo de coordinar y movilizar a los legisladores de la fórmula (core legislators), la tensión entre las leyes impulsadas y la maximización del voto a su favor se reduce notablemente.

Visto así, el papel de las comisiones permanentes, en entornos marcados por la ausencia de una mayoría estable, puede resumirse de la siguiente manera. Como punto de partida, las comisiones coordinan el proceso de información y discusión conducente a la reducción del número de iniciativas presentadas en torno a los temas de interés para los partidos. Al mismo tiempo, definen el texto de la propuesta que podría sumar la mayoría requerida para su aprobación en el Pleno. Cuando es necesario, persuaden a los legisladores todavía renuentes con la "recomendación", a la instancia encargada de distribuir el presupuesto, de conceder exenciones, o asignar fondos para servicios u obras públicas de interés territorial o sectorial, a cambio de su voto. Por último, movilizan el voto 
mediante la amenaza potencialmente efectiva de sustituir de la comisión a quienes persisten en obstruir o criticar las decisiones pactadas, lo que eleva el costo de mantener actitudes disidentes o incontrovertibles.

Ahora bien, aunque todos los miembros de la comisión participan en tales actividades, cabe estimar que los designados como sus "presidentes" destacan de los demás por varias razones. Una sería su actuación como canal autorizado por ley $-\mathrm{y}$ desde luego, por aquellos que, de acuerdo con esta, propusieron su designación para ocupar ese cargo- para comunicar la comisión tanto con el órgano encargado de controlar la agenda del Pleno, como con la autoridad designada por el Ejecutivo para impulsar su agenda en el Congreso.

Desde esta perspectiva, los responsables de dicha tarea se obligan a anticipar los problemas y las reacciones generadas como parte del proceso legislativo, y a establecer y procurar las medidas conducentes a lograr su solución. Su experiencia para el manejo de los conflictos de intereses detectados en el camino - ya de actores políticos, ya de grupos organizados de la sociedad-, y para la negociación de acuerdos constituye, de esta suerte, un referente indispensable en la evaluación de la eficiencia legislativa de la comisión bajo su mando.

\section{Las comisiones permanentes en México}

Durante mucho tiempo, el estudio de las comisiones permanentes del Congreso mexicano no fue un tema relevante para los especialistas. Las facultades que la norma asignaba para legislar tenían un valor más simbólico que efectivo por el dominio exhibido por el Ejecutivo federal sobre cualquier decisión relativa a esta tarea (González, 1964). Ese equilibrio era posible con base en tres factores. El primero, la capacidad de su partido, el Revolucionario Institucional (PRI), para garantizar con solamente el voto de sus legisladores la aprobación de sus iniciativas tanto en la Cámara de Diputados como en el Senado. Segundo, su actuación como el líder natural de ese instituto y, por tanto, como responsable de aprobar en última instancia la designación de sus candidatos para ocupar cualquier cargo de representación popular. Tercero, la existencia de un sistema electoral no competitivo, y por ende, cerrado a la alternancia en todos los niveles de gobierno.

Como resultado de ese arreglo, la construcción de acuerdos en los recintos parlamentarios con fuerzas de oposición, autoridades locales o dirigencias corporativas, era innecesaria. La lenta pero constante transformación del sistema electoral mexicano puso punto final a esa ecuación. Una clara señal de inflexión en ese sentido tuvo lugar en 1988, luego de que el PRI perdió la mayoría calificada para aprobar cualquier reforma constitucional. El último tramo del cambio 
en curso se concretó tras los comicios intermedios de 1997, una vez que ese partido perdió su condición de mayoría en la Cámara de Diputados.

En adelante, cualquier propuesta de legislación, independientemente de su origen, ha sido objeto de discusión y negociación con las fuerzas de oposición dispuestas a sumar y conseguir así la mayoría para su aprobación. En este contexto, la ausencia de restricciones en el artículo 71 de la Constitución para la presentación de iniciativas con cargo al Ejecutivo, senadores y diputados federales, y congresos locales, adicionado al imperativo de su dictaminación antes de ser votadas por el Pleno, transforma a las comisiones permanentes en un filtro clave para evitar el avance de propuestas sin el aval de los liderazgos partidistas. ${ }^{2}$

Para asegurar que esto ocurra, la Ley Orgánica del Congreso (LOC) y el Reglamento Interno de ambas cámaras (RIC) encargan a los coordinadores de grupos parlamentarios, a través de su participación en la Junta de Coordinación Política (JuCOPo), la realización de varias tareas claves. Entre ellas, negociar —al inicio de cada legislatura - el partido y legislador que ostentarán la presidencia de una comisión y la integración del listado de sus miembros, además de solicitar a la asamblea la sustitución de cualquiera de ellos, ya sea en forma temporal o definitiva. ${ }^{3}$ Advertidos estos últimos sobre los costos de mantener actitudes disidentes o insalvables, el camino para la elaboración de propuestas de ley susceptibles de sumar mayoría se ve despejado de obstáculos. ${ }^{4}$

La opción, por otra parte, de que las comisiones decidan con independencia a lo acordado por los líderes de las bancadas queda anulada, ya que la norma no las autoriza a incorporar directamente, o por medio de su presidente, sus dictámenes en el "orden del día" del Pleno. Mientras que, en la Cámara de Diputados, esa atribución corresponde a la Conferencia para la Dirección y la Programación de los Trabajos Legislativos (CDPTL) —órgano conformado por el presidente de la Mesa Directiva y la Jucopo- en el Senado, dicho sea de paso, esta es asumida por la segunda. ${ }^{5}$

2 Las reformas introducidas al artículo 71 de la Constitución Política de los Estados Unidos Mexicanos (CEUM) en 2012 omitieron la disposición constitucional de turnar a comisiones las iniciativas presentadas a consideración de los legisladores. El texto actual señala que la Ley del Congreso determinará el trámite que deba dárseles. El asunto es resuelto, sin embargo, a nivel reglamentario en el Senado con el artículo 173 y en la Cámara de Diputados, con el 102.

3 Artículos 39, numeral 2, y 43, numerales 3 y 4 para la Cámara de Diputados, y 82, inciso c, para el Senado.

4 Véanse los artículos 43, numeral 6, y 44, numeral 2, para la Cámara de Diputados, y 82 de la Ley Orgánica del Congreso General (LOCG).

5 Véanse los artículos 43, 44 y 83 de la LOcG. La diferencia del formato con que en cada caso se resuelve el asunto, no obstante, tiene pocas consecuencias en la práctica, puesto que en ambos cuerpos el control negativo de la agenda legislativa permanece en manos de los líderes de los grupos parlamentarios.

L. Béjar Algazi, S. Bárcena Juárez | El proceso legislativo en México: la eficiencia de las comisiones permanentes en un Congreso sin mayoría | Perfiles Latinoamericanos, 24(48) | Flacso México | pp. 111-140 
Más allá de la jerarquía trazada por la ley, en términos de la subordinación de sus decisiones a una lógica partidista, la relevancia recién adquirida por las comisiones permanentes queda claramente plasmada en la Loc aprobada un año antes de concluir la LVII legislatura (1997-2000). A diferencia de la norma vigente desde 1979 (Béjar, 2010), ahora se explicita que las comisiones permanentes podrán llevar a cabo las acciones que consideren necesarias para el cumplimiento de su labor. Esto incluye la solicitud de información a cualquier dependencia pública y la de la comparecencia de sus funcionarios ante la comisión, o de su titular ante el Pleno. ${ }^{6}$ En el mismo tenor, la ley establece con mayor precisión los parámetros relativos a su organización interna en lo relativo a la creación de subcomisiones, a su obligación de presentar un programa anual de trabajo y de informar semestralmente tanto de sus actividades, como de organizar y mantener un archivo de los asuntos que les fueron turnados.

Como parte de sus nuevas responsabilidades, las comisiones permanentes de la Cámara de Diputados adquieren también una obligación adicional: hacer llegar su opinión a la Comisión de Presupuesto y Cuenta Pública sobre el cumplimiento de los objetivos de los programas relativos a su ramo, con base en los informes presentados por el órgano encargado de fiscalizar las actividades del Ejecutivo federal y otras entidades públicas. ${ }^{7}$ Sin menosprecio de sus posibles aportaciones en ese aspecto, la medida permite que su presidente pueda "aceitar la maquinaria legislativa" (Evans, 2004). Dicho en otras palabras, tramite el intercambio de recursos por los votos necesarios para lograr la aprobación de leyes de amplio alcance (porkbarrel politics).

\section{La eficiencia de las comisiones permanentes en México}

Como ya se ha señalado, los estudios que básicamente se concentran en medir el número de dictámenes expedidos por las comisiones versus el número de iniciativas presentadas a su consideración para determinar la eficiencia de las comisiones o de la legislatura en general para elaborar la ley omiten la complejidad del esfuerzo exigido para el desarrollo de este proceso en ausencia de una mayoría estable y cohesionada. No es lo mismo atender esa tarea siempre con los mismos aliados que tener que buscar en cada ocasión la forma de conseguir su apoyo, sin que eso suponga riesgos de fractura interna en sus filas, por no haberse previsto las acciones conducentes a evitar esa situación. Este

6 Artículo 45, numerales 1 y 4. En lo relativo al Senado, artículos 93, numeral 1, y 97, numeral 1.

7 Véase artículo 45, numeral 5 de la LOCG. Sobre los términos de la fiscalización encomendada a la Cámara de Diputados a través de su sistema de comisiones, véase el artículo 79, fracción 1, de la CPEUM. 
juicio es confirmado con el testimonio de uno de los actores políticos llamado a participar directamente en el proceso de decisión de la ley.

Es ilógico calificar [la eficiencia de] una comisión por el número de dictámenes que produce. Hay iniciativas que tocan temas demasiado sensibles para los partidos o para ciertos grupos. Se siente cuando una iniciativa es importante porque tienes varios interesados asistiendo a las sesiones o buscando audiencias para dar su punto de vista sobre cómo debe salir el dictamen. Otras iniciativas exigen que se les trate con cuidado desde el lado técnico. Un error de terminología jurídico, o dejar algo suelto, como por ejemplo, no articular una ley secundaria con la Constitución, puede echarte a perder todo el trabajo que se hizo en la comisión. ${ }^{8}$

Si los señalamientos recogidos en la cita anterior dan cuenta clara de algunos de los retos involucrados en la empresa de legislar sin una mayoría estable y cohesionada, a ello hay que agregar que el desempeño de cada comisión se encuentra expuesto también a otras múltiples variables. Entre ellas, por solo nombrar algunas, el perfil profesional y político de sus miembros y de su presidente, y su relación con el gobierno; ello, además de la diversa naturaleza de los asuntos públicos bajo su jurisdicción tanto en lo relativo a su alcance, como en su conflictividad o su relevancia en determinadas coyunturas.

\section{Sobre el diseño de la investigación}

En tal entendido, el presente estudio propone un método distinto para capturar y evaluar la eficiencia legislativa de las comisiones permanentes del Congreso. Se trata de considerar no solo el número de iniciativas dictaminadas por aquellas en el plazo de una legislatura, sino también el número y tipo de sesiones requeridas para sacar adelante su aprobación final. Para esto, se revisó el trabajo de las 122 comisiones permanentes de la Cámara de Diputados, correspondientes a la LVIII (2000-2003), la LIX (2003-2006) y la LX legislaturas (2006-2009).?

8 Entrevista a la senadora panista de la LXII legislatura (2012-2018), Laura Angélica Rojas Hernández, realizada el lunes 8 de abril de 2013. La entrevistada ocupa el cargo de presidenta de la Comisión de Relaciones Exteriores, y es integrante de la Comisión de Anticorrupción y Participación Ciudadana, y de la Comisión de Cultura de esa Cámara. También ocupó el cargo de diputada federal en la Lxi legislatura (2009-2012).

9 Para el segmento empírico de este trabajo se utilizó la base de datos elaborada por el proyecto de investigación PAPIIT-IN305011: "Descentralización política y proceso legislativo en México", aprobado por la Dirección General de Apoyo al Personal Académico (DGAPA) y financiado por la UNAM. 
Con ese propósito se utilizaron los datos disponibles de dos fuentes: a) la Gaceta Parlamentaria del Sistema de Información Legislativa, y el Servicio de Información para la Estadística Parlamentaria (INFOPAL), ambos de la Cámara de Diputados, y b) el Sistema de Información Legislativa (sIL) de la Secretaría de Gobernación. ${ }^{10}$ En una primera etapa, se elaboró una base de datos a partir de las iniciativas turnadas y dictaminadas por cada comisión. A continuación, se clasificaron las reuniones y las actividades realizadas en ellas con base en su programa anual e informes semestrales de labores. Por último, de las fichas bibliográficas de sus presidentes, se seleccionaron los antecedentes profesionales y políticos pertinentes. Cada entrada fue llenada por dos personas. Los casos dudosos, o en los que se detectó discrepancia, se discutieron en conjunto para asegurar la homologación de criterios.

Dado que un dictamen puede incorporar varias iniciativas, el dato recogido en la base indica la cantidad de iniciativas dictaminadas positiva o negativamente por comisión en cada una de las tres legislaturas analizadas. Cuando ese proceso tuvo lugar bajo el formato de "comisiones unidas" solo se consignó el dictamen emitido por la comisión nombrada en primer término por la Mesa Directiva de la cámara. El número de reuniones recogió el total de las convocadas y con quórum suficiente para desahogar los asuntos incluidos en el "orden del día” de la sesión.

Las actividades incluidas en dicha agenda por cada comisión se exploraron a partir de un modelo previamente planteado por esta investigación. Bajo el rubro de coordinación se consignó el porcentaje del total de actividades para proveer a sus miembros de la información relativa a los temas abordados por la iniciativa, o iniciativas sujetas a dictaminación. Léase, comparecencias o consultas con funcionarios públicos, organización de seminarios, foros, conferencias, $u$ otros eventos similares. A través de estas, se da oportunidad a los interesados en influir en la ley, de que manifiesten sus preferencias sobre la forma de solucionar los asuntos que les afectan. Al mismo tiempo, los partidos pueden precisar sus posturas y fijar los términos de la negociación para apoyar con su voto la propuesta a ser votada por el Pleno.

Las actividades persuasivas refieren al porcentaje del total de reuniones destinadas a la atención de solicitudes de apoyo recibidas por la comisión para la asignación de recursos orientados a programas enfocados a sectores específicos de la población u obras públicas ubicadas en determinadas localidades o esta-

10 No se consideraron los casos de legisladores que, tras ser removidos de su cargo, posteriormente volvieron a ser reincorporados en la comisión. Asimismo, se excluyeron los cambios producidos por ausencias temporales (enfermedad, viajes o defunciones), o por separación del grupo al que pertenecía el legislador. 
dos del país. Por último, en sustituciones se apunta el porcentaje de remociones producidas con respecto a su membresía original en las siguientes modalidades: a) la baja de uno de sus integrantes, b) la incorporación de otro, y c) la modificación de su cuerpo directivo. ${ }^{11}$

La estrategia de investigación se cumplió con la siguiente ruta. Eliminadas las cuatro comisiones que no recibieron ninguna iniciativa en las tres legislaturas analizadas, las restantes fueron jerarquizadas en orden decreciente, de acuerdo al cociente obtenido de dividir el número de dictámenes expedidos por cada una entre el número de reuniones invertidas en esa empresa (véase el anexo 1). ${ }^{12}$ Efectuada esa operación, se seleccionaron las cinco comisiones "más eficientes" y las cinco "menos eficientes" en cada trienio con dos objetivos. El primero, reducir la varianza en los cocientes de eficiencia mostrado por el conjunto, así como asegurar mínimas condiciones de semejanza entre los casos analizados. El segundo, contrastar la forma en que las actividades realizadas en su seno y los cambios producidos en su integración original influyeron sobre el rendimiento legislativo de cada uno de estos dos segmentos (véanse los anexos 2 y 3 ).

En lo correspondiente a la trayectoria político-profesional de los presidentes de las cinco comisiones "más eficientes" y las cinco "menos eficientes" de cada legislatura, se examinó su paso previo por cargos de representación popular o de la administración pública en el ámbito federal y estatal a fin de establecer su experiencia en lo relativo al procesamiento e implementación de la ley. Por último, se registraron sus años de militancia partidista como vía para establecer su capacidad negociadora (véanse los anexos 4 y 5 ).

\section{Sobre el índice de eficiencia}

Desprendido de lo anterior, en la tabla 1 se advierte la existencia de un patrón compartido por las comisiones clasificadas como "más eficientes", y uno diverso, por las "menos eficientes" en las tres legislaturas analizadas. Con apenas alguna excepción, en el primer grupo se ubicaron las encargadas de atender la legislación de mayor alcance tanto en términos de la población, como de la extensión del territorio afectado por sus decisiones. Su esfera de jurisdicción reprodujo el esquema de organización y jerarquía definido por la administración pública federal, lo que quizás explica su aparición como las receptoras del

11 Las comisiones eliminadas fueron la de Vigilancia de la Auditoría Superior de la Federación en las LVIII y Lx legislaturas, y la de Fortalecimiento del Federalismo en las LIX y Lx legislaturas.

12 Las cinco comisiones más eficientes recibieron un promedio de 103, 334 y 251 iniciativas en las LVIII, LIX y LX legislaturas. En contraste, a las cinco menos eficientes se turnaron 2, 5.6 y 5.8, respectivamente. 
mayor número de iniciativas. ${ }^{13} \mathrm{El}$ manejo del tiempo y de las actividades realizadas durante las reuniones convocadas por su presidente, en consecuencia, debió ser más eficiente para garantizar la producción de dictámenes tendientes a dar salida a los asuntos de interés para la Jucopo.

Tabla 1. Índice de eficiencia de las comisiones legislativas seleccionadas

\begin{tabular}{|c|c|c|c|c|}
\hline \multirow[b]{2}{*}{ Legislatura } & \multicolumn{2}{|c|}{ Más eficientes } & \multicolumn{2}{|c|}{ Menos eficientes } \\
\hline & Nombre de la comisión & $\begin{array}{l}\text { Índice de } \\
\text { eficiencia }\end{array}$ & Nombre de la comisión & $\begin{array}{l}\text { Índice de } \\
\text { eficiencia }\end{array}$ \\
\hline \multirow{5}{*}{ LVIII } & Hacienda & 1.71 & Cultura & 0 \\
\hline & Justicia y derechos Humanos & .52 & Fortalecimiento... & 0 \\
\hline & Equidad y género & .50 & D. F. & 0 \\
\hline & Gobernación & .49 & Población, fronteras... & 0 \\
\hline & Comercio & .45 & Recursos hidráulicos & 0 \\
\hline \multirow{5}{*}{ LIX } & Régimen, reglamentos... & 1.50 & Asuntos indígenas & 0 \\
\hline & Hacienda & 1.42 & Desarrollo rural & 0 \\
\hline & Puntos constitucionales & 1.14 & Población, fronteras... & 0 \\
\hline & Salud & .849 & Desarrollo metropolitano & 0 \\
\hline & Gobernación & .450 & Turismo & 0 \\
\hline \multirow{5}{*}{$L X$} & Puntos constitucionales & 2.76 & Desarrollo metropolitano & 0 \\
\hline & Justicia & 2.71 & Fomento cooperativo & 0 \\
\hline & Gobernación & 2.20 & Marina & 0 \\
\hline & Función pública & 1.52 & Turismo & .01 \\
\hline & Régimen, reglamentos... & 1.27 & Comunicaciones & .02 \\
\hline
\end{tabular}

NOTA: En las legislaturas LVIII y LIX, las cinco comisiones reportadas como menos eficientes fueron las únicas que no produjeron ningún dictamen en las distintas reuniones destinadas para dicho objetivo.

Fuente: Elaboración propia con datos del Sistema de Información Legislativa (SIL), recuperado de http://sil.gobernacion. gob.mx/portal; y página oficial de la Cámara de Diputados, recuperado de http://www.diputados.gob.mx/

En contraste, las comisiones destacadas como las "menos eficientes" comparten al menos dos características. Por un lado, que su creación en principio responde al proceso de negociación puesto en marcha por los coordinadores de los grupos parlamentarios al inicio de cada legislatura en aras de cumplir con la proporcionalidad exigida por la ley. Esto, desde luego, sin descartar su interés en repartir de esta manera beneficios y prebendas a cambio de disciplina, o en canalizar la influencia de determinados actores sobre algún tipo de legislación. Por el otro, que los asuntos encomendados a sus miembros muestran un impacto focalizado y muchas veces coyuntural, lo que, dicho sea de paso, bien pudiera desalentar el interés de elevar la eficiencia de su comisión.

13 Los niveles de homogeneidad de las varianzas dentro de los grupos definidos por tipo de actividad justifican esta operación. 
Ahora bien, más que patrones rígidos e inmutables, el estudio esboza algunas tendencias mediadas por múltiples factores. Entre ellos, por ejemplo, la visibilidad coyuntural o el grado de conflictividad de los problemas abordados por cada comisión. Este sería el caso de la comisión del D. F. —incluida en la lista de las "menos eficientes" en la LVIII legislatura - la que, a pesar de atender cuestiones relevantes para la capital del país, pudiera mostrar proclividad a figurar como escenario de disputas partidistas.

Por otro lado, se observa que las comisiones "más eficientes" se hacen todavía "más eficientes" con el avance de una legislatura a otra. En este sentido, el conjunto alcanza un promedio de .734 dictámenes por reunión en la LVIII (2000-2003), para ascender a 1.054 en la LIx (2003-2006), y llegar a 2.09 en la LX (2006-2009). Su índice de eficiencia habría experimentado así un incremento de $185 \%$ en solo seis años. El dato podría sugerir también la incorporación de ajustes en sus actividades a efecto de elevar su producción de dictámenes por reunión. A este respecto, no está de más recordar la ausencia de incentivos para el aprendizaje organizacional ya que al término de cada legislatura tanto los integrantes de cada comisión como el personal de apoyo técnico son relevados en su totalidad.

Sobre las actividades realizadas por las comisiones

Para medir las actividades de coordinación, persuasión y movilización en las comisiones permanentes se calcularon las medias aritméticas por trienio de las actividades informativas y las enfocadas al intercambio de votos por recursos. Todo ello de acuerdo al "orden del día" de las reuniones llevadas a cabo por las comisiones de los dos conjuntos analizados. Este procedimiento se repite en lo correspondiente a las sustituciones en su membresía. Por ilustrar el caso, si en las cinco comisiones "más eficientes" de la LVIII legislatura los porcentajes de actividades informativas realizadas por cada comisión hubieran sido $10 \%$ para una comisión y 50, 20, 10 y $20 \%$ para las otras cuatro, respectivamente, la calificación (media aritmética) asignada al conjunto de comisiones más eficientes sería de $22 \%$ o .22 .

Lo primero que se observa en la tabla 2 es que las actividades de coordinación permanentemente son un rubro de diferenciación entre las comisiones "más eficientes" y las "menos eficientes". En los tres trienios analizados, el comportamiento del primer grupo muestra una tendencia inversa a la exhibida por el segundo. Con cada nueva legislatura, mientras en uno el promedio se reduce, al pasar del 0.432 en la LVIII, al 0.177 en la LIX, y al 0.070 en la LX, en el otro, este se incrementa en forma consistente $(0.273,0.407,0.490)$. 
Tabla 2. Gestiones de las comisiones legislativas seleccionadas. Media aritmética por legislatura

\begin{tabular}{l|ccc|ccc}
\hline & \multicolumn{3}{|c|}{ Más eficientes } & \multicolumn{3}{c}{ Menos eficientes } \\
\hline Legislatura & Coordinación & Persuasión & Movilización & Coordinación & Persuasión & Movilización \\
\hline LVIII & 0.432 & 0.055 & 0.193 & 0.273 & 0.059 & 0.278 \\
LIX & 0.177 & 0.011 & 0.381 & 0.407 & 0.031 & 0.398 \\
\hline LX & 0.070 & 0.0 & 0.391 & 0.490 & 0.071 & 0.263 \\
\hline
\end{tabular}

Fuente: Elaboración propia con datos del SIL y la Gaceta Parlamentaria de la Cámara de Diputados.

Ambos registros permiten estimar que uno de los componentes básicos de la eficiencia de las comisiones es la acotación de las actividades enfocadas a proveer de información a sus miembros con dos objetivos. Primero, para evitar la dispersión de las propuestas y los respaldos concitados por estas. Segundo, para acelerar la expedición de un dictamen con posibilidad de ser aprobado por una mayoría. En el mismo sentido, demuestra el rápido aprendizaje de los liderazgos partidistas sobre cómo organizar la elaboración de los dictámenes para evitar el riesgo de parálisis por la ausencia de una mayoría estable en el Congreso.

En contraste, las comisiones concentradas en resolver sobre cuestiones de menor impacto también parecen ser las que despiertan menor interés en elevar la tasa de rendimiento legislativo de sus miembros. En ellas, el consumo de más tiempo para informar, discutir y elaborar una propuesta de ley susceptible de acceder a la agenda del Pleno es mayor al requerido por el conjunto de las "más eficientes". Presumiblemente, este resultado podría ser consecuencia del poco interés mostrado por los coordinadores de los grupos parlamentarios en ejercer un mejor control sobre sus actividades. De igual modo, permite suponer que quizás la diversificación de las fuentes de información referidas a determinados problemas no facilita necesariamente el proceso de toma de decisiones.

Las actividades de las comisiones "más eficientes" encaminadas a favorecer el intercambio de votos por recursos —o si se quiere, a persuadir a los indecisos- en las tres legislaturas examinadas representan una proporción mucho menor que las informativas. El sesgo descendiente mostrado por las segundas confirmaría igualmente la incorporación de ajustes en los procedimientos para asegurar la formulación de dictámenes. En adición, aunque en las "menos eficientes" el promedio de las "persuasivas" varía en cada uno de los trienios, su comportamiento no es muy diferente al del otro segmento.

En cualquier caso, los datos podrían indicar que, a diferencia de experiencias como la estadounidense (Evans, 2004), en México la construcción de mayorías para la aprobación de leyes de amplio alcance descansa menos en esa estrategia, que en la capacidad de los coordinadores para imponer la disciplina en su bancada a través de las disposiciones previstas por el marco institucional del Congreso. Ello, sin embargo, no descarta la aplicación de políticas distributivas en México, 
sino simplemente que las comisiones permanentes no son el espacio natural para su negociación, por una sencilla causa: la legislación no exige que la aprobación de cualquier ley, como en Estados Unidos, suponga asegurar por anticipado la provisión de los recursos necesarios para su implementación.

Por otra parte, el promedio de "remociones" o "sustituciones" alcanzado entre las comisiones "más eficientes" y las "menos eficientes", tampoco muestra variación. Con respecto a las primeras, eso indicaría que los líderes parlamentarios usan de manera regular su facultad de designar a los miembros de las comisiones, o de su cuerpo directivo, para movilizar el voto en el Pleno. Después de todo, el recurso puede ser utilizado estratégicamente, lo mismo para impulsar que para impedir la elaboración de un dictamen. En consecuencia, el constante incremento en el uso de este mecanismo, observado en los tres trienios analizados $(0.193,0.381$ y 0.391 , respectivamente), puede ser interpretado como un signo del creciente control de los coordinadores sobre la agenda legislativa del Pleno por medio de las comisiones permanentes.

En lo que toca a las "menos eficientes", es claro que a pesar de ser menos relevantes para el partido, el empeño de mantener la disciplina en su seno tampoco debe ser desestimado $(0.278,0.398,0.263)$. En este caso, sin embargo, no cabe desechar la posibilidad de que la alta tasa de "sustituciones" experimentada por este segmento responda también al desinterés de sus miembros por asistir a sus sesiones, o por participar en las actividades realizadas en su seno. Lo que sí es seguro es que la abundancia de sustituciones tanto de las comisiones "más eficientes", como en las "menos eficientes", afecta la calidad del trabajo legislativo, sobre todo en un Congreso como el mexicano, privado durante largo tiempo de la experiencia que la reelección consecutiva pudiera alentar en sus miembros.

\section{Sobre los presidentes de las comisiones}

Para evaluar el impacto de la trayectoria político-profesional de sus presidentes sobre la eficiencia de las comisiones a su cargo, el estudio compara el promedio de años invertidos previamente por aquellos vinculados a las cinco comisiones "más" y "menos" eficientes de cada legislatura en tres rubros: a) cargos de representación en la legislatura federal (diputado o senador) o estatal, $b$ ) en la administración pública, también en ambos niveles, y c) en militancia en sus respectivos partidos (véase el anexo 4). ${ }^{14} \mathrm{La}$ idea que orienta esta sección es, como

14 El indicador de experiencia legislativa se midió con base en el total de años que los presidentes de comisión fungieron como diputados locales, federales o senadores titulares en forma previa. La experiencia 
ya se dijo, que quienes presiden una comisión destacan como actores relevantes en el proceso legislativo al figurar como el principal canal de comunicación entre sus integrantes y los liderazgos partidistas. En este sentido, su intervención permite tanto prevenir posibles nudos de conflicto por intereses opuestos, como impulsar las acciones conducentes a facilitar su solución.

Según se aprecia en la tabla 3, el elemento diferenciador de las comisiones "más" y "menos" eficientes es la experiencia adquirida por su conductor durante su carrera política en cargos de la administración pública federal. Este hallazgo se comprueba con la aplicación de distintas pruebas estadísticas (véase el anexo 5). Su capacidad para anticipar problemas potenciales con el Poder Ejecutivo, autoridad encargada de implementar la ley, constituye, en consecuencia, un factor clave de eficiencia legislativa. A este respecto, conviene recordar que, aunque privado del apoyo disciplinado de una mayoría de su partido, el gobierno también forma parte del "cartel" encargado de decidir el rumbo de la ley (Chasquetti, 2011), por su poder para vetar cualquier disposición aprobada por el Congreso, a su juicio, inaceptable.

La experiencia legislativa en el ámbito federal es menos importante en el trienio que acompaña la primera mitad del mandato del presidente Felipe Calderón Hinojosa (2006-2009) que en los dos anteriores. En estos, haber ocupado un cargo en la legislatura o la administración pública estatal tiene mayor relevancia, lo que podría indicar la importancia de los liderazgos subnacionales de los partidos en el modelo de negociación presente en el Congreso federal. En forma complementaria, demostraría la capacidad de la dirigencia nacional para reaccionar frente a esta situación, y retomar el control del proceso legislativo en forma más o menos rápida.

Tabla 3. Años de experiencia de los presidentes de las comisiones seleccionadas. Media aritmética por legislatura

\begin{tabular}{|c|c|c|c|c|c|c|c|c|c|c|}
\hline \multirow{2}{*}{$\begin{array}{l}\text { Legislatura } \\
\text { Eficiencia }\end{array}$} & \multicolumn{2}{|c|}{$\begin{array}{c}\text { Experiencia } \\
\text { legislativa a nivel } \\
\text { federal }\end{array}$} & \multicolumn{2}{|c|}{$\begin{array}{c}\text { Experiencia } \\
\text { legislativa a nivel } \\
\text { estatal }\end{array}$} & \multicolumn{2}{|c|}{$\begin{array}{c}\text { Experiencia en AP } \\
\text { a nivel federal }\end{array}$} & \multicolumn{2}{|c|}{$\begin{array}{c}\text { Experiencia en AP } \\
\text { a nivel estatal }\end{array}$} & \multicolumn{2}{|c|}{$\begin{array}{c}\text { Experiencia } \\
\text { por militancia } \\
\text { partidista }\end{array}$} \\
\hline & $\begin{array}{c}\text { Más } \\
\text { eficientes }\end{array}$ & $\begin{array}{c}\text { Menos } \\
\text { eficientes }\end{array}$ & $\begin{array}{c}\text { Más } \\
\text { Eficientes }\end{array}$ & $\begin{array}{c}\text { Menos } \\
\text { eficientes }\end{array}$ & $\begin{array}{c}\text { Más } \\
\text { Eficientes }\end{array}$ & $\begin{array}{c}\text { Menos } \\
\text { eficientes }\end{array}$ & $\begin{array}{c}\text { Más } \\
\text { eficientes }\end{array}$ & $\begin{array}{c}\text { Menos } \\
\text { eficientes }\end{array}$ & \begin{tabular}{|c} 
Más \\
eficientes
\end{tabular} & $\begin{array}{l}\text { Menos } \\
\text { eficientes }\end{array}$ \\
\hline LVIII & 0.6 & 0.6 & 0.6 & 1.2 & 6.8 & 1.4 & 0.6 & 6.2 & 9.8 & 15.4 \\
\hline LIX & 0.6 & 0.6 & 3 & 1.8 & 3.2 & 0 & 8.6 & 1.6 & 16.8 & 10 \\
\hline$L X$ & 6.6 & 1.8 & 0.6 & 2.4 & 6.4 & 1.2 & 3.8 & 4.8 & 14.8 & 13.8 \\
\hline
\end{tabular}

Fuente: Elaboración propia con datos del SIL y de la página oficial de la Cámara de Diputados.

en la administración pública corresponde a la suma total de ańos en que estos ocuparon algún cargo en el gobierno federal, estatal y/o municipal. Finalmente, la experiencia partidista registra el total de años en que han militado en la fórmula correspondiente al grupo parlamentario del cual forman parte. 
Algo que llama la atención es que, a partir de la urx legislatura (2003-2006), la experiencia adquirida durante los años de militancia partidista también comporte un elemento de diferenciación entre las comisiones "más" eficientes de las "menos". Dada la dificultad de llegar a acuerdos, esto pudiera interpretarse como una cualidad adicional del liderazgo nacional de los partidos para evitar el estancamiento legislativo, más cuando el notorio incremento en el número de iniciativas presentadas por los diputados en el trienio hace urgente la implementación de las estrategias de coordinación tendientes a allanar la dictaminación de piezas de interés para su organización. ${ }^{15}$

\section{A modo de conclusión}

Sin mayoría en el Congreso, las comisiones permanentes están llamadas a realizar un papel muy distinto al que suelen tener en contextos políticos en los que esa condición sí está presente. Cuando el gobierno cuenta con el apoyo cohesionado y suficiente de su partido para lograr la aprobación de su agenda política no hace falta la negociación con otras fuerzas políticas. Si acaso, este debe asegurar internamente que sus iniciativas no afecten los intereses de sus militantes, o de otros aliados eventuales de la sociedad civil organizada afectada por las disposiciones que se busca incorporar en la ley.

En el otro escenario - ausencia de un partido en posesión de una mayoría de escaños-, su contribución en la definición de los términos para la expedición de una reforma o una nueva ley es fundamental. Para conseguirlo, según la evidencia recabada en el caso del Congreso mexicano, su tarea consiste en coordinar la información sobre los asuntos incorporados a la agenda legislativa tanto por el Ejecutivo, como por todas las fórmulas partidistas con capacidad de determinar el éxito o no fracaso de una propuesta. Coordinar, sin embargo, no solo significa aquí organizar y procurar información para que los partidos definan el sentido de su voto, sino también acotar la información relativa a cualquier tema a fin de evitar la dispersión de posturas en dos sentido: uno, de las opciones de interpretación de los problemas objeto de atención por parte de los legisladores; dos, de las posibles formas de tratar de darles solución.

15 En la LVIII legislatura, la Cámara de Diputados recibe 1025 iniciativas de las cuales en comisiones se dictaminan 444, correspondientes al 43.3\% del total. Por su parte, el Pleno aprueba 305, lo que equivale al 29.7\%. En la LIx, sin embargo, el número de iniciativas presentadas se eleva a 2939, de las cuales se dictaminan 1213 (41.3\%) y se aprueban 403 (13.7\%). Lo anterior indicaría un cambio en el patrón de comportamiento de los legisladores, cada vez más interesados en labrarse una reputación personal a través de esta actividad, pero no de los liderazgos partidistas en alentar esa conducta.

L. Béjar Algazi, S. Bárcena Juárez | El proceso legislativo en México: la eficiencia de las comisiones permanentes en un Congreso sin mayoría | Perfiles Latinoamericanos, 24(48) | Flacso México | pp. 111-140 
En el mismo sentido, el estudio demuestra que desde las comisiones permanentes de la Cámara de Diputados se puede persuadir a los políticos más resistentes a aceptar los términos de la negociación del texto susceptible de alcanzar el voto de la mayoría en el Pleno. Desde luego, la intensidad con que este mecanismo es utilizado varía de un caso a otro. Esto se comprueba al analizar la experiencia norteamericana, pero también la de varios países de América Latina. Entre ellos, vale la pena destacar el caso brasileño en el que los recursos a que puede acceder un legislador por esta vía se encuentran contemplados en la ley (Pereira \& Müller, 2004). En la misma dirección, tampoco parece exagerado suponer que la asignación de fondos u otros privilegios otorgados a los afectados por los costos de una negociación es algo que ocurre en todos los países democráticos. Ahora bien, cuando ni los argumentos ni las compensaciones son suficientes para lograr la aceptación de un acuerdo, hacer efectivas las facultades que la ley confiere al liderazgo político para sustituir, o dicho en palabras llanas, hacer a un lado a los "intransigentes", puede constituir una buena salida del problema.

Las consecuencias de los Congresos sin mayoría desde luego desborda el tipo de actividades que sus comisiones permanentes deben realizar en esas circunstancias. De igual manera, es difícil comprender cabalmente los efectos que esto tiene sobre su productividad legislativa, y sobre la eficiencia con que cada comisión cumple esa encomienda. Como en casi todos los temas, las explicaciones responden a una dinámica multifactorial (Saiegh, 2010). A pesar de ello, cualquier esfuerzo en esa dirección contribuye a despejar algunas incógnitas, aunque siempre surjan otras.

Uno de los aspectos más importantes llevaría a precisar la forma en que el contenido de la legislación se ve afectada por la intervención de las comisiones en la elaboración de las propuestas aprobadas por el Pleno. ¿La calidad de la ley se ve incrementada o disminuida al limitar su discusión? ¿Hasta dónde su condición de "filtro" evita la incorporación de asuntos relevantes para amplios segmentos de la población en la agenda decisoria del Congreso? ¿De qué manera se alienta o se trata de eludir el sesgo presente en casi cualquier pieza de legislación (Cobb \& Elder, 1977)? Las preguntas aún sin responder son muchas. Otras investigaciones tendrán que intentar avanzar en su respuesta. 


\section{Referencias}

Aldrich, J. H. \& Rohde, D. W. (2001). The Logic of Conditional Party Government: Revisiting the Electoral Connection. En Dodd, L. C. \& Oppenheimer, B. I. Congress Reconsidered (pp. 269-292). Washington, D. C.: CQ Press.

Alemán, E. (2006). Policy Gatekeepers in Latin American Legislatures. Latin American Politics and Society, 48(3), 125-155.

Aparicio, F. J. \& Langston, J. (2010). Committee Leadership in Mexico’s Chamber of Deputies, 1997-2006. Trabajo presentado en la conferencia anual de la Midwest Political Science Association, Chicago, Illinois.

Béjar, L. (2010). De la centralización a la descentralización. El nuevo diseño institucional del Congreso de la Unión. Foro Internacional, 50(1), 115-145.

Béjar, L. (2009). Elites parlamentarias en México. Los presidentes comisiones. En Béjar, L. (Coord.). ¿Qué se legisla en México? El trabajo en comisiones (pp 65-98). México: Porrúa.

Calvo, E. \& Sagarzazu, I. (2011a). El rol de las comisiones permanentes en las legislaturas de América Latina: un test del modelo informativo de éxito legislativo. Revista Latinoamericana de Politica Comparada, (4), 25-48.

Calvo, E. \& Sagarzazu, I. (2011b, enero). Legislator Success in Committee: Gatekeeping Authority and the Loss of Majority Control. American Journal of Political Science, 55(1), 1-15.

Casar, M. A. (2008). Los gobiernos sin mayoría en México: 1997-2006. Politica y Gobierno, 15(2), 221-270.

Carey, J. M. (2009). Legislative Voting and Accountability. Nueva York: Cambridge University Press.

Chasquetti, D. (2011). El secreto del éxito: presidentes y cárteles legislativos en Uruguay (19952010). Revista Uruguaya de Ciencia Politica, 20(1), 1-19.

Crisp, B. F., Escobar-Lemmon, M. C., Jones, B. S., Jones, M. P. \& Taylor-Robinson, M. M. (2009). The Electoral Connection and Legislative Committees. Journal of Legislative Studies, 15(1), 35-52.

Crisp, B. F., Escobar-Lemmon, M. C., Jones, B. S., Jones, M. P. \& Taylor-Robinson, M. M. (2004). Vote-Seeking Incentives and Legislative Representation in Six Presidential Democracies. Journal of Politics, 66(3), 823-846.

L. Béjar Algazi, S. Bárcena Juárez | El proceso legislativo en México: la eficiencia de las comisiones permanentes en un Congreso sin mayoría | Perfiles Latinoamericanos, 24(48) | Flacso México | pp. 111-140 
Cobb, R. \& Elder, Ch. D. (1971). The Politics of Agenda-Building: An Alternative Perspective for Modern Democratic Theory. Journal of Politics, 33(4), 892-915.

Cox, G. W. (2009). Swing Voters, Core Voters, and Distributive Politics. En Shapiro, I., Stokes, S., Wood, E. J. \& Kirshner, A. (Coords.). Political Representation (pp. 342-357). Nueva York: Cambridge University Press.

Cox, G. W. \& McCubbins, M. D. (2005). Setting the Agenda: Responsible Party Government in the US House of Representatives. Nueva York: Cambridge University Press.

Cox, G. W. \& McCubbins, M. D. (1993). Legislative Leviathan: Party Government in the House. Berkeley: University of California Press.

Dávila, D. \& Caballero, L. (2005). El sistema de comisiones, el cabildeo y la participación ciudadana en el Congreso mexicano. México: Fundar Centro de Análisis e Investigación.

Desposato, S. W. (2004). The Impact of Federalism on National Parties in Brazil. Legislative Studies Quarterly, 29(2), 259-285.

Díaz-Cayeros, A. (2004). Do Federal Institutions Matter? Rules and Political Practices in Regional Resource Allocation in México. En Gibson, E. (Coord.). Federalism and Democracy in Latin America (pp. 297-322). Baltimore: Johns Hopkins University Press.

Evans, D. (2004). Greasing the Wheels. Using Pork Barrel Projects to Build Majority Coalitions in Congress. Cambridge: Cambridge University Press.

Jones, M. P. \& Hwang, W. (2004). Party Government in Presidential Democracies: Extending Cartel Theory Beyond the U.S. Congress. American Journal of Political Science, 49(2), 267-282.

Méndez de Hoyos, I. (2006). Transición a la Democracia en México. Competencia partidista y reformas electorales 1977-2003. México: Flacso México/Fontamara.

Merino, M. (2010). Nuevo federalismo, nuevos conflictos. En Loaeza, S. \& Prud'homme, J. F. (Coords.). Los grandes problemas de México. Instituciones y procesos politicos, XIV, (pp. 488529). México: El Colegio de México.

Nacif, B. (2004). Las relaciones entre los poderes ejecutivo y legislativo tras el fin del presidencialismo en México. Política y Gobierno, 11(1), 9-41.

Nacif, B. (2000). El sistema de comisiones permanentes en la Cámara de Diputados de México. Documento de Trabajo núm. 116. México: Centro de Investigación y Docencia Económicas (CIDE). 
Pereira, C. \& Müller, B. (2004). A Theory on Executive Dominance of Congressional Politics: The Committee System in the Brazilian Chamber of Deputies. Journal of Legislative Studies, 10(1), 9-49.

Puente, K. (2009). De la productividad legislativa la eficiencia parlamentaria en el sistema de comisiones en el Senado Mexicano. En Béjar, L. (Coord.). ¿Qué hacen los legisladores en México? (pp. 99-127). México: unam/Porrúa.

Rivera, J. A. (2004). Cambio institucional y democratización. La evolución de las comisiones en la Cámara de Diputados de México. Política y Gobierno, 11(2), 263-313.

Saiegh, S. (2010). ¿Jugadores activos o apéndices del ejecutivo? Una evaluación del papel de los legisladores latinoamericanos en la toma de decisiones. Política y Gobierno, 17(1), 3-24.

Santos, F. \& Renno, L. (2004). The Selection of Committee Leadership in the Brazilian Chamber of Deputies. Journal of Legislative Studies, 10(1), 50-70.

Stokes, S. (2004). Perverse Accountability: A Formal Model of Machine Politics with Evidence from Argentina. American Political Science Review, 99(3), 315-325.

Weldon, J. (2002). Las fuentes políticas del presidencialismo en México. En Mainwaring, S. \& Soberg Shugart, M. (Comps.). Presidencialismo y democracia en América Latina (pp. 175211). Buenos Aires: Paidós. 


\section{Anexos metodológicos}

\section{Valores del índice de eficiencia. Dictámenes/reuniones de cada comisión. Resultados por legislatura.}

NoTA: Las diez comisiones seleccionadas por legislatura aparecen en un recuadro.

\section{Legislatura LVIII}

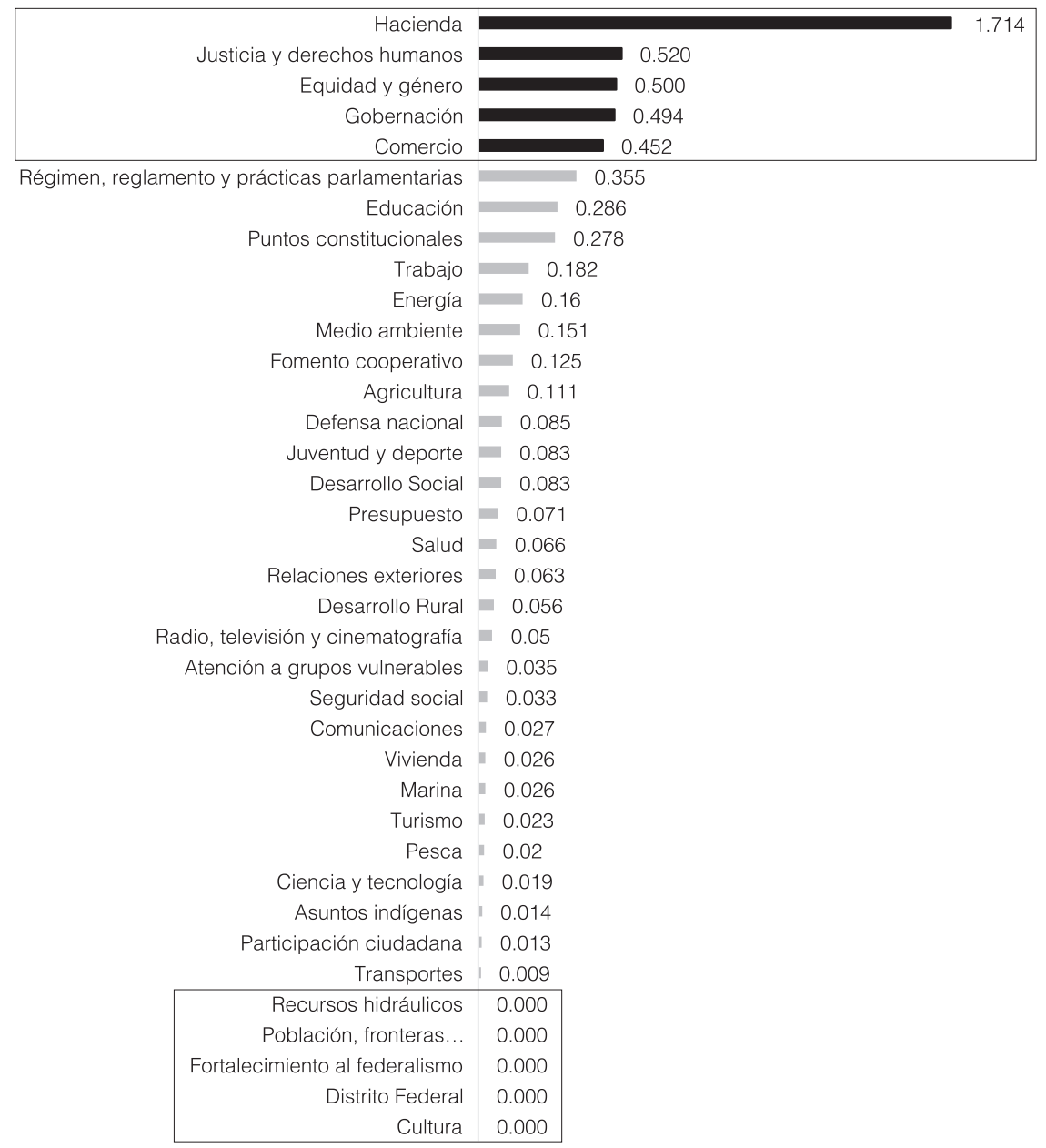




\section{Legislatura LIX}

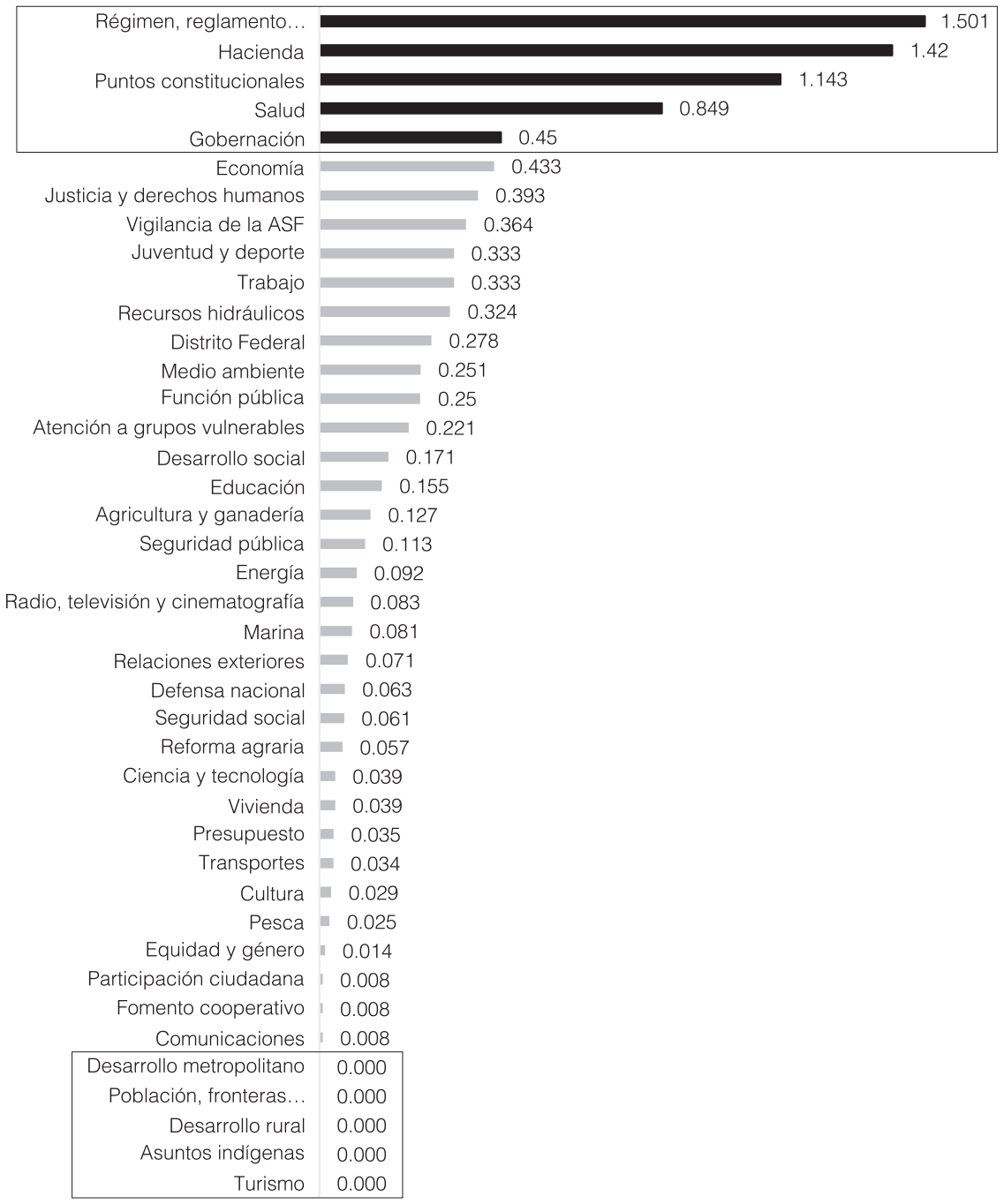

L. Béjar Algazi, S. Bárcena Juárez | El proceso legislativo en México: la eficiencia de las comisiones permanentes en un Congreso sin mayoría | Perfiles Latinoamericanos, 24(48) | FLacso México | pp. 111-140 


\section{Legislatura $L X$}

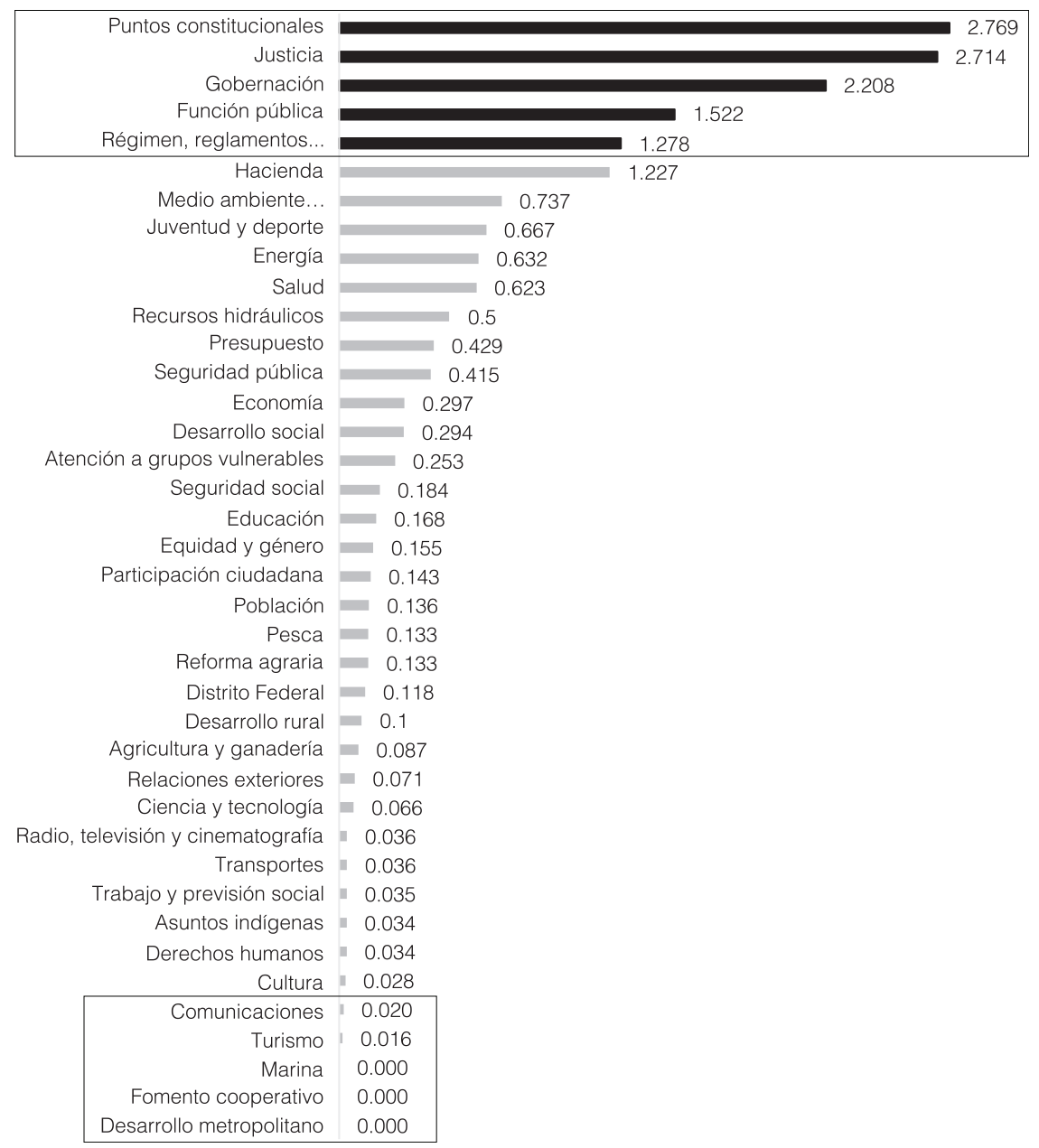

134 L. Béjar Algazi, S. Bárcena Juárez | El proceso legislativo en México: la eficiencia de las comisiones permanentes en un Congreso sin mayoría | Perfiles Latinoamericanos, 24(48) | Flacso México | pp. 111-140 DoI: $10.18504 / \mathrm{pl} 2448-005-2016$ 
2. Estadísticos descriptivos de comisiones por índice de eficiencia

Todos los índices. Legislaturas LVIII-LX $(n=122)$

\begin{tabular}{llll}
\hline & LVIII & LIX & LX \\
\hline Media & .157 & .232 & .446 \\
Varianza & .089 & .125 & .500 \\
Desviación estándar & .298 & .354 & .707 \\
\hline
\end{tabular}

Cinco comisiones con mayor índice. Todos los índices. Legislaturas LVIII-LX

\begin{tabular}{lccc}
\hline & LVIII & LIX & LX \\
\hline Media & .740 & 1.105 & 2.100 \\
Varianza & .301 & .169 & .462 \\
Desviación estándar & .549 & .411 & .680 \\
\hline
\end{tabular}

Cinco comisiones con menor índice, Todos los índices. Legislaturas LVIII-LX

\begin{tabular}{lccc}
\hline & LVIII & LIX & LX \\
\hline Media & 0 & 0 & .010 \\
Varianza & 0 & 0 & 0 \\
Desviación estándar & 0 & 0.003 & .010 \\
\hline
\end{tabular}

3. Pruebas de normalidad por esquema probit para la calificación de eficiencia por comisiones. Resultados por legislatura.

NotA: El eje "y", llamado "iel” o índice de eficiencia legislativa, es el resultado de dividir dictámenes entre reuniones de comisión.

Tras correr las pruebas se observó que, en promedio, el 80\% de las calificaciones de efectividad se encontraron por debajo de la media, generando fuertes asimetrías y una notable concentración de casos en cuartiles bajos. Asimismo, fue recurrente en todas las legislaturas que unos cuantos casos se desprendieran de la distribución, dada la superioridad comparativa de sus valores. Esta particular distribución de los valores de eficiencia por comisión (variable dependiente del presente estudio) imposibilitó la realización de posteriores análisis de correlación basados en el supuesto de linealidad. 
LVIII legislatura

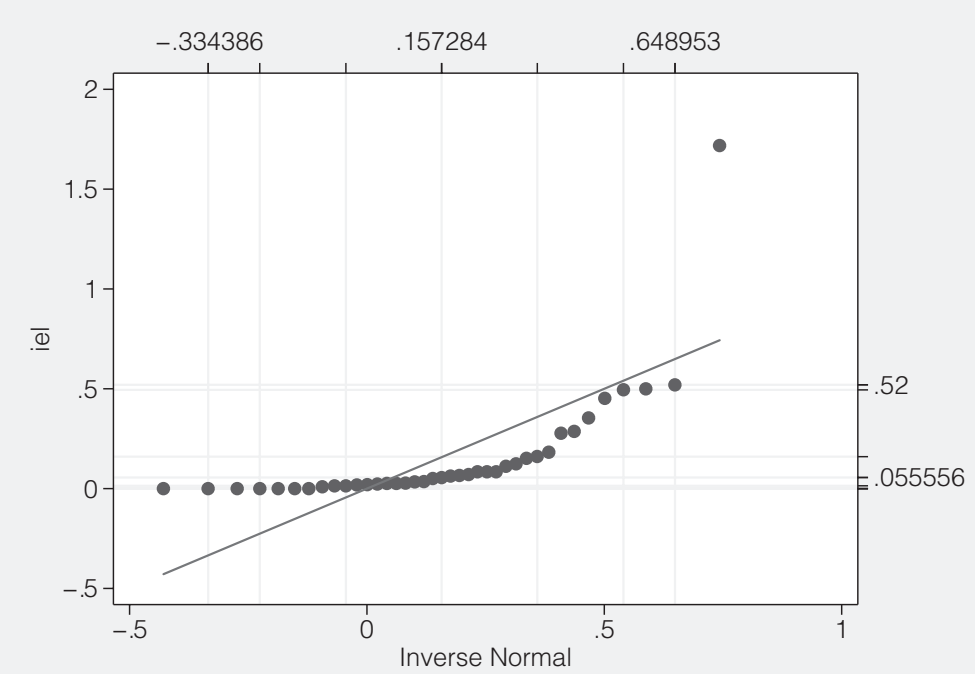

Grid lines are 5, 10, 25, 50, 75, 90, and 95 percentiles

LIX legislatura

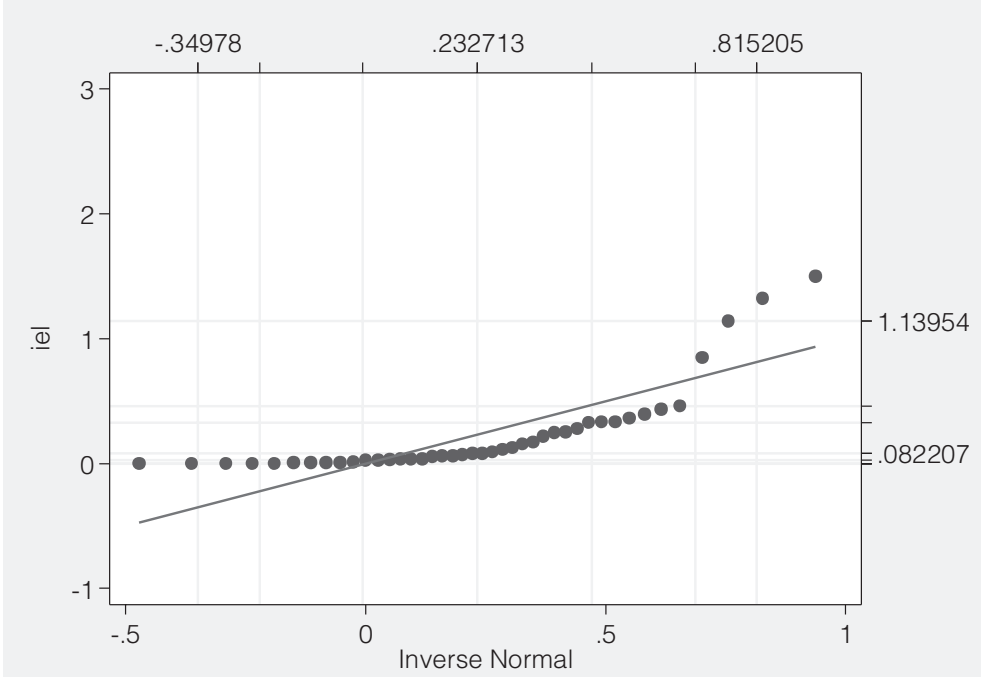

Grid lines are 5, 10, 25, 50, 75, 90, and 95 percentiles 


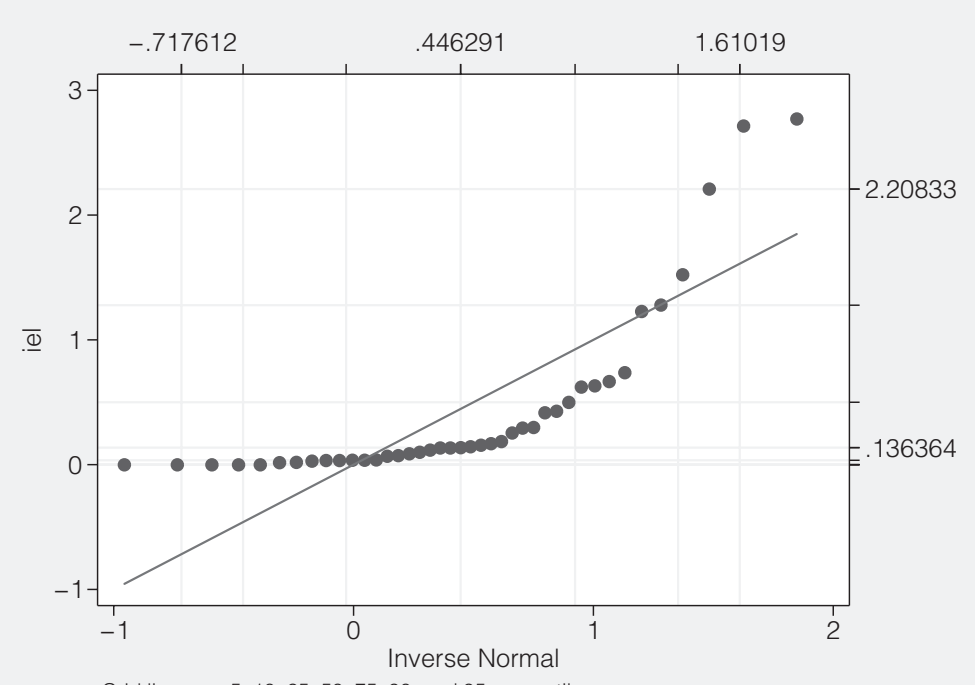

Grid lines are 5, 10, 25, 50, 75, 90, and 95 percentiles

\section{Información biográfica de presidentes de comisiones seleccionadas por legislatura. Estadísticos descriptivos}

LVIII legislatura. Comisiones más eficientes

\begin{tabular}{lccccccc}
\hline Comisión & $\begin{array}{c}\text { Experiencia } \\
\text { legislativa } \\
\text { total }\end{array}$ & $\begin{array}{c}\text { Experiencia } \\
\text { legislativa } \\
\text { federal }\end{array}$ & $\begin{array}{c}\text { Experiencia } \\
\text { legislativa } \\
\text { local }\end{array}$ & $\begin{array}{c}\text { Experiencia } \\
\text { gubernamen- } \\
\text { tal total }\end{array}$ & $\begin{array}{c}\text { Experiencia } \\
\text { gubernamen- } \\
\text { tal federal }\end{array}$ & $\begin{array}{c}\text { Experiencia } \\
\text { guberna- } \\
\text { mental local }\end{array}$ & $\begin{array}{c}\text { Años de } \\
\text { militancia } \\
\text { partidista }\end{array}$ \\
\hline Hacienda & 0 & 0 & 0 & 21 & 21 & 0 & 12 \\
Justicia & 3 & 3 & 0 & 16 & 13 & 3 & 15 \\
$\begin{array}{l}\text { Equidad y } \\
\text { género }\end{array}$ & 3 & 0 & 3 & 3 & 0 & 0 & 15 \\
Gobernación & 0 & 0 & 0 & 5 & 0 & 0 & 3 \\
Comercio & 0 & 0 & 0 & 4 & 0 & 0 & 4 \\
Media & 1.2 & 0.6 & 0.6 & 9.8 & 6.8 & 0.6 & 9.8 \\
Desv. estándar & 1.6 & 1.3 & 1.3 & 8.2 & 9.7 & 1.3 & 5.9 \\
Varianza & 2.7 & 1.8 & 1.8 & 66.7 & 94.7 & 1.8 & 34.7 \\
\hline
\end{tabular}


LVIII legislatura. Comisiones menos eficientes

\begin{tabular}{lccccccc}
\hline Comisión & $\begin{array}{c}\text { Experiencia } \\
\text { legislativa } \\
\text { total }\end{array}$ & $\begin{array}{c}\text { Experiencia } \\
\text { legislativa } \\
\text { federal }\end{array}$ & $\begin{array}{c}\text { Experiencia } \\
\text { legislativa } \\
\text { local }\end{array}$ & $\begin{array}{c}\text { Experiencia } \\
\text { guberna- } \\
\text { mental total }\end{array}$ & $\begin{array}{c}\text { Experiencia } \\
\text { gubernamen- } \\
\text { tal federal }\end{array}$ & $\begin{array}{c}\text { Experiencia } \\
\text { guberna- } \\
\text { mental local }\end{array}$ & $\begin{array}{c}\text { Años de } \\
\text { militancia } \\
\text { partidista }\end{array}$ \\
\hline Cultura & 9 & 3 & 6 & 19 & 0 & 16 & 37 \\
D. F. & 0 & 0 & 0 & 0 & 0 & 0 & 4 \\
$\begin{array}{l}\text { Fortalecimiento } \\
\text { al federalismo }\end{array}$ & 0 & 0 & 0 & 11 & 0 & 9 & 13 \\
$\begin{array}{l}\text { Población, } \\
\text { fronteras... }\end{array}$ & 0 & 0 & 0 & 5 & 0 & 3 & 9 \\
$\begin{array}{l}\text { Recursos } \\
\text { hidráulicos }\end{array}$ & 0 & 0 & 0 & 12 & 7 & 3 & 14 \\
Media & 1.8 & 0.6 & 1.2 & 9.4 & 1.4 & 6.2 & 15.4 \\
Desv. estándar & 4.0 & 1.342 & 2.7 & 7.2 & 3.1 & 6.4 & 12.7 \\
Varianza & 16.2 & 1.8 & 7.2 & 52.3 & 9.8 & 40.7 & 161.3 \\
\hline
\end{tabular}

LIX legislatura. Comisiones más eficientes

\begin{tabular}{lccccccc}
\hline Comisión & $\begin{array}{c}\text { Experiencia } \\
\text { legislativa } \\
\text { total }\end{array}$ & $\begin{array}{c}\text { Experiencia } \\
\text { legislativa } \\
\text { federal }\end{array}$ & $\begin{array}{c}\text { Experiencia } \\
\text { legislativa } \\
\text { local }\end{array}$ & $\begin{array}{c}\text { Experiencia } \\
\text { guberna- } \\
\text { mental total }\end{array}$ & $\begin{array}{c}\text { Experiencia } \\
\text { gubernamen- } \\
\text { tal federal }\end{array}$ & $\begin{array}{c}\text { Experiencia } \\
\text { guberna- } \\
\text { mental local }\end{array}$ & $\begin{array}{c}\text { Años de } \\
\text { militancia } \\
\text { partidista }\end{array}$ \\
\hline $\begin{array}{l}\text { Régimen, } \\
\text { reglamento... }\end{array}$ & 6 & 3 & 3 & 3 & 0 & 0 & 14 \\
Hacienda & 3 & 0 & 3 & 13 & 8 & 5 & 4 \\
$\begin{array}{l}\text { Puntos } \\
\text { constitucionales }\end{array}$ & 3 & 0 & 3 & 17 & 8 & 9 & 35 \\
Salud & 0 & 0 & 0 & 24 & 0 & 24 & 1 \\
Gobernación & 6 & 0 & 6 & 7 & 0 & 5 & 30 \\
Media & 3.6 & 0.6 & 3.0 & 12.8 & 3.2 & 8.6 & 16.8 \\
Desv. estándar & 2.5 & 1.3 & 2.1 & 8.3 & 4.4 & 9.2 & 15.2 \\
Varianza & 6.3 & 1.8 & 4.5 & 68.2 & 19.2 & 84.3 & 231.7 \\
\hline
\end{tabular}

LIX legislatura. Comisiones menos eficientes

\begin{tabular}{lccccccc}
\hline Comisión & $\begin{array}{c}\text { Experiencia } \\
\text { legislativa } \\
\text { total }\end{array}$ & $\begin{array}{c}\text { Experiencia } \\
\text { legislativa } \\
\text { federal }\end{array}$ & $\begin{array}{c}\text { Experiencia } \\
\text { legislativa } \\
\text { local }\end{array}$ & $\begin{array}{c}\text { Experiencia } \\
\text { guberna- } \\
\text { mental total }\end{array}$ & $\begin{array}{c}\text { Experiencia } \\
\text { gubernamen- } \\
\text { tal federal }\end{array}$ & $\begin{array}{c}\text { Experiencia } \\
\text { guberna- } \\
\text { mental local }\end{array}$ & $\begin{array}{c}\text { Años de } \\
\text { militancia } \\
\text { partidista }\end{array}$ \\
\hline $\begin{array}{l}\text { Asuntos } \\
\text { indígenas }\end{array}$ & 0 & 0 & 0 & 5 & 0 & 0 & 13 \\
$\begin{array}{l}\text { Desarrollo } \\
\text { rural }\end{array}$ & 3 & 0 & 3 & 6 & 0 & 6 & 13 \\
$\begin{array}{l}\text { Población, } \\
\text { fronteras... }\end{array}$ & 6 & 3 & 3 & 4 & 0 & 0 & 1 \\
$\begin{array}{l}\text { Desarrollo } \\
\text { metropolitano }\end{array}$ & 3 & 0 & 3 & 15 & 0 & 2 & 20 \\
$\begin{array}{l}\text { Turismo } \\
\text { Media }\end{array}$ & 0 & 0 & 0 & 0 & 0 & 0 & 3 \\
$\begin{array}{l}\text { Desv. } \\
\text { estándar }\end{array}$ & 2.4 & 0.6 & 1.8 & 6.0 & 0.0 & 1.6 & 10.0 \\
Varianza & 2.5 & 1.3 & 1.6 & 5.5 & 0.0 & 2.6 & 7.8 \\
\hline
\end{tabular}

138 L. Béjar Algazi, S. Bárcena Juárez | El proceso legislativo en México: la eficiencia de las comisiones permanentes en un Congreso sin mayoría | Perfiles Latinoamericanos, 24(48) | FLAcso México | pp. 111-140

DOI: $10.18504 / \mathrm{pl} 2448-005-2016$ 
LX legislatura. Comisiones más eficientes

\begin{tabular}{lccccccc}
\hline Comisión & $\begin{array}{c}\text { Experiencia } \\
\text { legislativa } \\
\text { total }\end{array}$ & $\begin{array}{c}\text { Experiencia } \\
\text { legislativa } \\
\text { federal }\end{array}$ & $\begin{array}{c}\text { Experiencia } \\
\text { legislativa } \\
\text { local }\end{array}$ & $\begin{array}{c}\text { Experiencia } \\
\text { guberna- } \\
\text { mental total }\end{array}$ & $\begin{array}{c}\text { Experiencia } \\
\text { gubernamen- } \\
\text { tal federal }\end{array}$ & $\begin{array}{c}\text { Experiencia } \\
\text { guberna- } \\
\text { mental local }\end{array}$ & $\begin{array}{c}\text { Años de } \\
\text { militancia } \\
\text { partidista }\end{array}$ \\
\hline $\begin{array}{l}\text { Puntos } \\
\text { constitucionales }\end{array}$ & 12 & 9 & 3 & 4 & 0 & 4 & 17 \\
$\begin{array}{l}\text { Justicia } \\
\text { Gobernación }\end{array}$ & 6 & 6 & 0 & 13 & 1 & 9 & 27 \\
$\begin{array}{l}\text { Función } \\
\text { pública }\end{array}$ & 6 & 6 & 0 & 15 & 15 & 0 & 1 \\
$\begin{array}{l}\text { Régimen, } \\
\text { reglamento... }\end{array}$ & 6 & 6 & 0 & 20 & 16 & 0 & 16 \\
Media & 7.2 & 6 & 0 & 6 & 0 & 6 & 13 \\
Desv. estándar & 2.7 & 1.3 & 1.3 & 6.6 & 8.3 & 3.9 & 9.3 \\
Varianza & 7.2 & 1.8 & 1.8 & 43.3 & 69.3 & 15.2 & 87.2 \\
\hline
\end{tabular}

LX legislatura. Comisiones menos eficientes

\begin{tabular}{lccccccc}
\hline Comisión & $\begin{array}{c}\text { Experiencia } \\
\text { legislativa } \\
\text { total }\end{array}$ & $\begin{array}{c}\text { Experiencia } \\
\text { legislativa } \\
\text { federal }\end{array}$ & $\begin{array}{c}\text { Experiencia } \\
\text { legislativa } \\
\text { local }\end{array}$ & $\begin{array}{c}\text { Experiencia } \\
\text { guberna- } \\
\text { mental total }\end{array}$ & $\begin{array}{c}\text { Experiencia } \\
\text { gubernamen- } \\
\text { tal federal }\end{array}$ & $\begin{array}{c}\text { Experiencia } \\
\text { guberna- } \\
\text { mental local }\end{array}$ & $\begin{array}{c}\text { Años de } \\
\text { militancia } \\
\text { partidista }\end{array}$ \\
\hline $\begin{array}{l}\text { Desarrollo } \\
\text { metropolitano }\end{array}$ & 9 & 6 & 3 & 0 & 0 & 0 & 12 \\
$\begin{array}{l}\text { Fomento } \\
\text { cooperativo }\end{array}$ & 0 & 0 & 0 & 9 & 0 & 4 & 18 \\
Marina & 3 & 0 & 3 & 14 & 4 & 10 & 7 \\
Turismo & 0 & 0 & 0 & 3 & 0 & 0 & 6 \\
Comunicaciones & 9 & 3 & 6 & 14 & 2 & 10 & 26 \\
Media & 4.2 & 1.8 & 2.4 & 8.0 & 1.2 & 4.8 & 13.8 \\
Desv. estándar & 4.5 & 2.7 & 2.5 & 6.4 & 1.8 & 5.0 & 8.3 \\
Varianza & 20.7 & 7.2 & 6.3 & 40.5 & 3.2 & 25.2 & 69.2 \\
\hline
\end{tabular}

5. Pruebas U de Mann-Whitney para contrastar años de experiencia legislativa, gubernamental y partidista por eficiencia de las comisiones (separadas en dos grupos de las 15 más y las 15 menos eficientes de las legislaturas LVIII-LIX).

Nota: Los resultados de las cinco pruebas sugieren que únicamente existe una diferencia estadísticamente significativa entre los años de experiencia gubernamental federal de los presidentes de comisiones relevantes y los años de experiencia gubernamental federal de los presidentes de comisiones menos eficientes a un nivel de $\mathrm{p}<.05$, sugiriendo, por la suma de rangos, que los presidentes de las comisiones más eficientes reportaron una mayor experiencia administrativa a nivel federal que los presidentes de las comisiones consideradas como menos eficientes en el presente estudio. 
Experiencia legislativa federal

Ho: Experiencia legislativa federal (más eficientes=menos eficientes)

\begin{tabular}{lccc}
\hline Tipo & Obs & Rank sum & Exp \\
\hline Más eficiente & 15 & 262 & 232.5 \\
Menos eficiente & 15 & 203 & 232.5 \\
$\mathrm{z}=1.425$ & & & \\
Prob $>|\mathrm{z}|=.1542$ & & & \\
\hline
\end{tabular}

Experiencia legislativa local

Ho: Experiencia legislativa local (más eficientes=menos eficientes)

\begin{tabular}{lccc}
\hline Tipo & Obs & Rank sum & Exp \\
\hline Más eficiente & 15 & 222.5 & 232.5 \\
Menos eficiente & 15 & 242.5 & 232.5 \\
$\mathrm{z}=-.469$ & & & \\
Prob $>|\mathrm{z}|=.638$ & & & \\
\hline
\end{tabular}

Experiencia gubernamental federal

Ho: Experiencia administrativa federal (más eficientes=menos eficientes)

\begin{tabular}{lccc}
\hline Tipo & Obs & Rank sum & Exp \\
\hline Más eficiente & 15 & 270 & 232.5 \\
Menos eficiente & 15 & 195 & 232.5 \\
$z=1.854$ & & & \\
Prob $>|z|=.0437$ & & & \\
\hline
\end{tabular}

Experiencia gubernamental local

Ho: Experiencia administrativa local (más eficientes=menos eficientes)

\begin{tabular}{lccc}
\hline Tipo & Obs & Rank sum & Exp \\
\hline Más eficiente & 15 & 227 & 232.5 \\
Menos eficiente & 15 & 238 & 232.5 \\
$z=-.238$ & & & \\
Prob $>|z|=.8116$ & & & \\
\hline
\end{tabular}

Experiencia partidista (años de militancia)

Ho: Experiencia partidista (más eficientes=menos eficientes)

\begin{tabular}{lccc}
\hline Tipo & Obs & Rank sum & Exp \\
\hline Más eficiente & 15 & 239 & 232.5 \\
Menos eficiente & 15 & 226 & 232.5 \\
$z=-.270$ & & & \\
Prob $>|z|=.7870$ & & & \\
\hline
\end{tabular}

Recibido el 17 de agosto de 2014. Aceptado el 3 de junio de 2015. 